\title{
Development of the pharmacogenomics and genomics literacy framework for pharmacists
}

\author{
Azhar T. Rahma1, Iffat Elbarazi ', Bassam R. Ali ${ }^{2,3}$, George P. Patrinos ${ }^{2,3,4}$, Luai A. Ahmed ${ }^{1,3}$, Mahanna Elsheik ${ }^{1,3}$ and \\ Fatma Al-Maskari ${ }^{1,3 *}$
}

\begin{abstract}
Background: Pharmacists play a unique role in integrating genomic medicine and pharmacogenomics into the clinical practice and to translate pharmacogenomics from bench to bedside. However, the literature suggests that the knowledge gap in pharmacogenomics is a major challenge; therefore, developing pharmacists'skills and literacy to achieve this anticipated role is highly important. We aim to conceptualize a personalized literacy framework for the adoption of genomic medicine and pharmacogenomics by pharmacists in the United Arab Emirates with possible regional and global relevance.
\end{abstract}

Results: A qualitative approach using focus groups was used to design and to guide the development of a pharmacogenomics literacy framework. The Health Literacy Skills framework was used as a guide to conceptualize the pharmacogenomics literacy for pharmacists. The framework included six major components with specific suggested factors to improve pharmacists' pharmacogenomics literacy. Major components include individual inputs, demand, skills, knowledge, attitude and sociocultural factors.

Conclusion: This framework confirms a holistic bottom-up approach toward the implementation of pharmacogenomics. Personalized medicine entails personalized efforts and frameworks. Similar framework can be created for other healthcare providers, patients and stakeholders.

Keywords: Framework, Genomics, Pharmacogenomics, Pharmacists, United Arab Emirates, Knowledge, Attitude, Skills, Literacy

\section{Introduction}

Pharmacogenomics (PGx) is a rapidly growing field of personalized medicine focusing on the effect of genetic variation in drug response [1,2]. It aims to improve drug efficacy and minimize adverse drug reactions (ADRs) [3-5]. ADR is defined as "any response to a drug which is noxious and unintended, and which occurs at doses normally used in man for prophylaxis, diagnosis, or

*Correspondence: fatma.am@uaeu.ac.ae

${ }^{1}$ Institute of Public Health, College of Medicine and Health Sciences, United Arab Emirates University, P.O. Box 17666, Al Ain, Abu Dhabi, UAE

Full list of author information is available at the end of the article therapy of disease, or for the modification of physiological function. [6]" For example, several retrospective and prospective studies show a strong association between the presence of HLA-B*57:01 allele and abacavir-induced hypersensitivity reaction [7-9]. Therefore, screening for the allele is highly recommended according to the FDAapproved drug label before administering the medication [10].

Prescribing the right drug with the right dose to the patient from the first time is the anchor of PGx and personalized medicine [11]. The American Society of HealthSystem Pharmacists (ASHP) highlighted, emphasized and detailed the responsibilities, roles and functions of original author(s) and the source, provide a link to the Creative Commons licence, and indicate if changes were made. The images or other third party material in this article are included in the article's Creative Commons licence, unless indicated otherwise in a credit line to the material. If material is not included in the article's Creative Commons licence and your intended use is not permitted by statutory regulation or exceeds the permitted use, you will need to obtain permission directly from the copyright holder. To view a copy of this licence, visit http://creativecommons.org/licenses/by/4.0/. The Creative Commons Public Domain Dedication waiver (http://creativeco mmons.org/publicdomain/zero/1.0/) applies to the data made available in this article, unless otherwise stated in a credit line to the data. 
the pharmacists in the PGx era [12]. Pharmacists lead a unique role in integrating PGx into the clinical practice and translate PGx from bench to bedside. This role has been extensively investigated in research and assessed in many models in the pragmatic field of oncology, cardiology, psychiatry, geriatric and pediatric medicine [13-21]. Nevertheless, pharmacists are lagging in fostering and implementing their anticipated role.

Studies show that pharmacists are faced with a plethora of needs, challenges and barriers that obstruct them from rising up to expectations. The literature emphasizes pharmacogenomic knowledge gap as a major challenge. In a study that interviewed pharmacists by Berenbrok et al. [22], participants stressed the importance of training, solid clinical resources and gaining access to PGx specialists to bridge the gap in their current knowledge of PGx.

Numerous studies have concluded that PGx literacy is the most cited barrier by pharmacists for the full implementation of PGx in the health setting; most of the pharmacists did not thoroughly study PGx during their coursework [23-25]. A study by Romagnoli et al. [26] stated that pharmacists demanded designing PGx tools as a vital step to facilitate the implementation of PGx in their workplace. Furthermore, in our assessment of the PGx knowledge of healthcare providers in the United Arab Emirates (UAE), respondents in our cohort echoed the same call [27].

Pharmacists strive for the synthesis of a framework to tackle their PGx literacy to facilitate the full implementation of PGx. The literature supports this-an article by Wurcel et al. [28] called for a model and framework to bridge the gap and smooth the implementation of diagnostic information in the era of personalized medicine.

There is conflict among researchers about the definition of health literacy. For the PGx literacy, we define it based on Baker [29] as "the dynamic skills needed to work in the health care setting." Baker (2006) states that health literacy is context specific and fluctuates depending on the type of health problem, provider, and setting. Also, genetic literacy has been defined as "adequate understanding and awareness of a genomics foundation to permit knowledgeable outcomes on genetic issues" [30].

The Health Literacy Skills framework (HLS) of Squiers et al. [31] is a comprehensive framework that appreciates the dynamic nature of knowledge and skills. The HLS has been conceptualized based on existing theoretical concepts and evolved by addressing the limitation of these concepts. The HLS framework is targeted toward patients and individuals, and it ties health literacy with health outcomes. Moreover, it factors the influence of society, culture, family, media and infrastructure on health literacy.
The HLS framework can steer interventions endeavoring health literacy. It is structured upon four main pillars: individual factors that impact literacy skills, stimuli for literacy, skills to understand and act upon stimuli and lastly mediators, facilitators and influences.

However, limited studies propose a personalized framework for pharmacists and other healthcare providers addressing their PGx literacy. In this article, the pharmacogenomics/genomics literacy framework for pharmacists (PGLP) is introduced-a personalized literacy framework for the adoption of PGx by healthcare providers concerned with genomics in UAE with possible regional and global relevance. This framework will guide stakeholders in their mission of equipping pharmacists, genetic counselors, doctors and nurses with skills required for the adoption and implementation of PGx.

\section{Materials and methods}

The HLS framework captures a holistic approach toward literacy and takes into account individual and sociocultural influences; therefore, it was utilized to conceptualize the PGLP framework [31]. Moreover, it was used as a guide to develop a personalized framework to be used among pharmacists. A qualitative method was used to design and guide the formation of the PGLP literacy framework. Four focus group discussions were organized with inpatient, outpatient, clinical and resident pharmacists working in the UAE. The interview guide was structured based on the HLS framework. The guide explored PGx knowledge, attitude and practice of pharmacists and the future of genomics and PGx fields. All discussions were coded and intercoder reliability was ensured. NVivo 12 software was used to extract themes and visualize the findings. Detailed methodology about recruitment and logistics is available in our previous research [27]. This study was approved by Social Science Research Ethics Committee of United Arab Emirates University ERS_2017_5671.

\section{Findings}

The pharmacogenomics/genomics literacy framework for pharmacists (PGLP) were conceptualized based on the themes, codes and associations extracted and analyzed from the focus group discussions [27].

The main themes and subthemes of pharmacists' PGx knowledge and attitudes extracted from the focus group discussions are shown in Figs. 1 and 2 respectively.

\section{Knowledge}

Over a third of the participants perceived their current knowledge and understanding of PGx and genomics to be poor. They also reported having limited knowledge on where genetic testing is conducted in the UAE. 

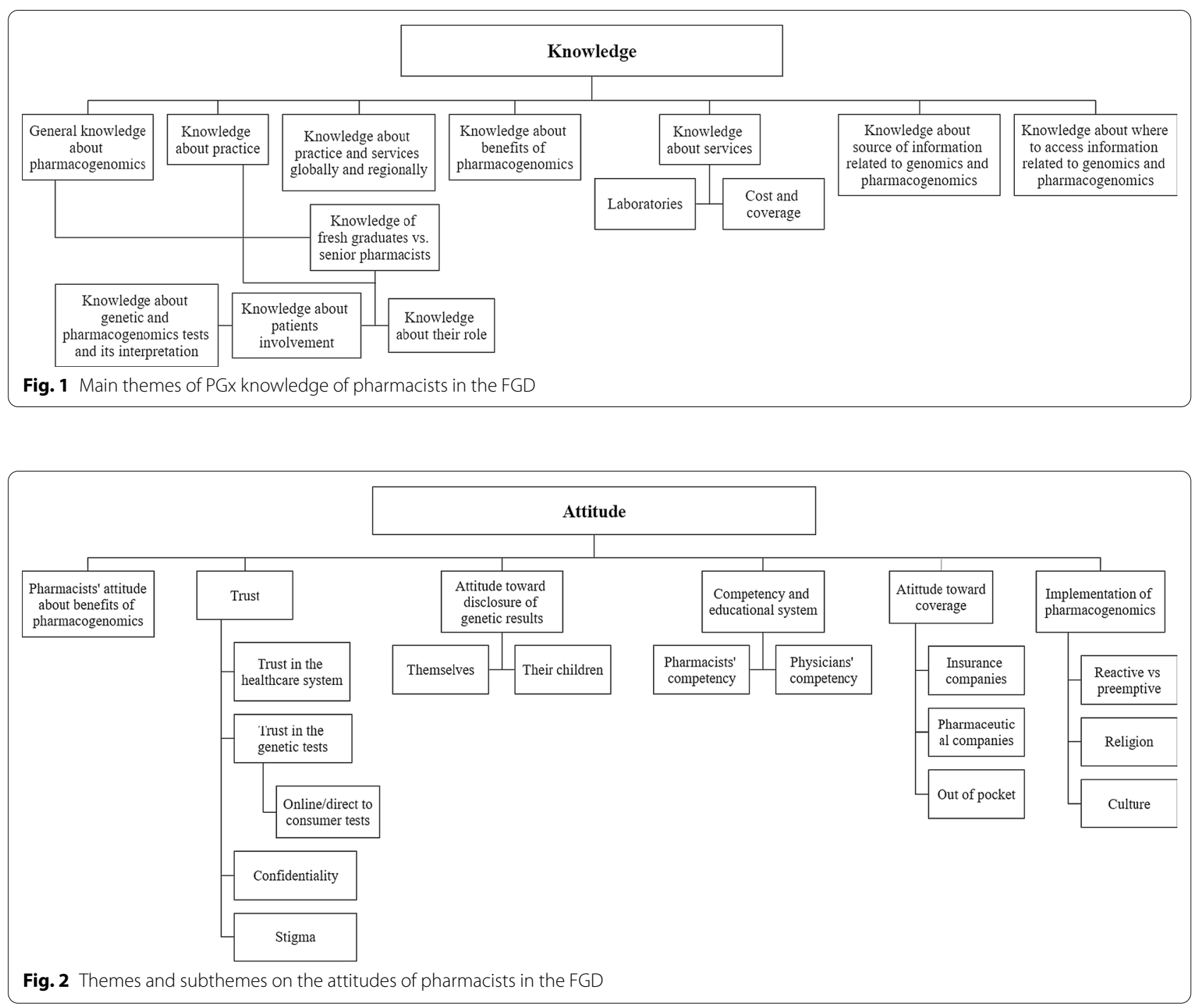

When questioned on their higher education, both seniorand entry-level pharmacists stated they did not receive any formal education on PGx or genomics during their undergraduate pharmacy program. All clinical pharmacists noted a gap in the availability of resources by the UAE health authorities regarding information on genomics. Outpatient pharmacists were more familiar with the cost and accessibility of genetic testing.

\section{Attitudes}

The majority of the pharmacists exhibited a positive attitude toward PGx despite their perceived lack of knowledge. However, there were some mixed responses on genetic testing. Some pharmacists were reluctant due to the possible discrimination and stigmatization associated with certain genetic diseases and the impact it could have on their social and family lives. Others viewed it as a protective measure allowing them to seek medical interventions and modify health behaviors in the case of a predisposition to a disease. Religious and cultural beliefs were noted as a potential barrier to the implementation of PGx in UAE.

When inquired on their skill and ability in interpreting genetic test reports, all pharmacists agreed they were not completely inept.

The main themes of knowledge and attitudes constitute the main pillars of the PGLP framework which are consistent with the components of the HLS framework including: (1) the individual input of pharmacists, (2) demand for genomics' literacy, (3) skills needed to improve illiteracy, (4) knowledge of the pharmacists about genomics/PGx and its applications, (5) attitudes of pharmacists and (6) sociocultural influences (Fig. 3). 


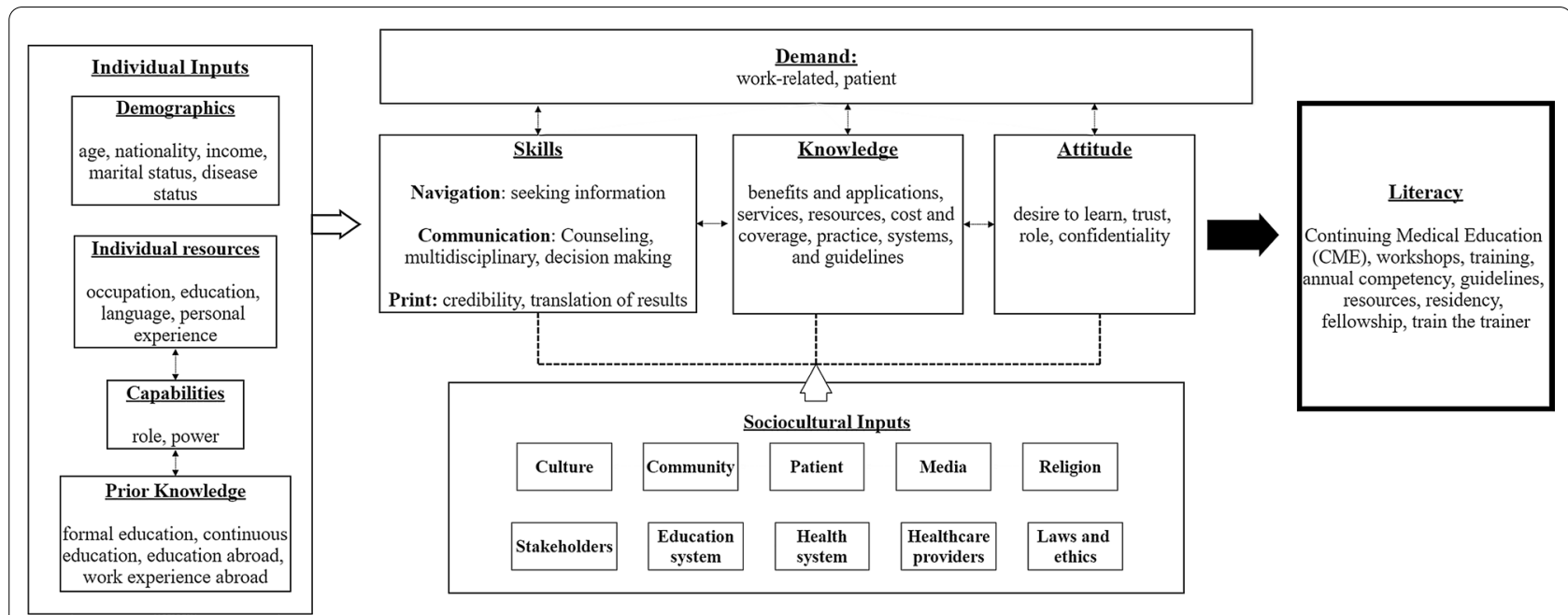

Fig. 3 Pharmacogenomics/genomics literacy framework for pharmacists (PGLP)

\section{Discussion}

The framework was centered on pharmacists since they are the core of PGx as articulated in the statement of The ASHP [12]. In this proposed PGLP framework, building $\mathrm{PGx} /$ genomics literacy for pharmacists depends on the following pillars:

\section{Individual inputs to literacy}

Both the HLS and PGLP framework embrace the individual traits as input into literacy. An individual's inputs like age, education, power, roles and capabilities are traits that need to be acknowledged and factored in while designing any training in any field and PGx is not an exception. One uniform approach has been abandoned and replaced by more tailored and personalized approaches that put the learner as the center and consider an individual's inherited factors and capabilities to empower them [25, 32-35]. Many medical and health sciences colleges are embracing this evidence-based shift in paradigm by tailoring the pedagogy according to the learner's individual traits [36-40].

In the PGLP framework, the diversity of pharmacists' roles, power and capabilities is explored. For example, clinical pharmacists were more familiar with PGx than pharmacists in community settings. Also, pharmacists with children were keener to learn about PGx as they appreciate and foresee its value. Therefore, stakeholders planning a PGx workshop for pharmacists need to know their audience in regard to demographic, role, occupation, prior knowledge and experiences. We hypothesize that this will be a cost-effective PGx literacy approach [41-43]. A study by Owusu-Obeng et al. explored the role of pharmacists in the PGx era and the findings aligned with ours. In their model, some of the individual inputs required from pharmacists were education, skills in informatics, background in medication safety, insight in medication-use policies and procedures and conquest of literature assessment [13].

In the published PGx implementation models, in accordance with our findings, clinical pharmacists were appropriately situated to implement and lead clinical PGx programs, as they possess credible individual inputs such as prior knowledge and expertise in pharmacodynamics, kinetics, genomics, informatics and patient care $[13,44-48]$.

\section{Demand or stimuli}

Our PGLP framework adopted the "demand" element from the HLS framework as it is the switch on button toward increasing genomic literacy and PGx implementation. The demand can originate from the patient and/ or the clinical setting in a micro-, meso- and macro-level [21]. The ASHP statements highlighted the pharmacist's patient-care loop. In their statement, patients were at the center stage for the demand for PGx implementation [12]. The demand is demonstrated by the interviewed pharmacists' positive outlooks on genomic medicine and PGx despite their knowledge gap. Moreover, previous research shows that stakeholders emphasize clinical demand for genomic medicine in the UAE considering the high prevalence of consanguinity and high burden of genetic diseases [49-51].

\section{Skills}

Critical skills of accessing, understanding, appraising and applying knowledge and information are an essential dimension of health literacy [30, 31, 52]. A study by 
Peterson-Clark et al. [53] pointed out that pharmacists scored a wide-ranging but shallow general skills in surfing online information and e-health. A randomized clinical trial by Basheti et al. [54] reported that the retention of the skills of the pharmacists was significantly improved after training them on the proper technique of using inhalers and providing them with printed materials and tools. These findings are in congruence with our findings [27]. It is pivotal to include the "skills" element to the PGLP framework as electronic resources and databases, like Clinical Pharmacogenetics Implementation Consortium (CPIC) and PharmGKB, are the mainstay of PGx $[55,56]$.

\section{Knowledge}

Knowledge of pharmacists is a profound repertoire of literacy. It was eluded in the HLS framework; however, we advocate and anchor its impact on health literacy in general and PGx/genomics in particular. Breadth of studies highlighted the $\mathrm{PGx} /$ genomics knowledge gap among pharmacists and other healthcare providers and the impact of this gap on implementation [22, 27, 57, 58].

In our PGLP framework, knowledge beyond an individual's prior knowledge of PGx/genomics is emphasized. This encompasses knowledge of benefits and applications of PGx, available resources, services and practices, cost and insurance coverage and knowledge of the local, national and international guidelines. We foresee it as a dynamic pillar that needs to be addressed regularly by stakeholders planning literacy in PGx/genomics. Knowledge will speed the implementation and adoption of $\mathrm{PGx} /$ genomics in the practice setting of pharmacists. Pharmacists' literacy and competency in PGx/genomics ought to be assessed and updated regularly [12, 22, 5860]. Therefore, this component of the PGLP framework is vital. Credibility of the healthcare provider, in our case the pharmacists, has been quoted as being essential to the patient and community's trust of any health information [31, 61, 62]. Thus, pharmacists' knowledge of PGx will assert such trust from patients and community [27].

\section{Attitude}

The HLS framework posed attitudes, feelings, incentive and self-worth as mediators between health literacy and outcome [31]. In our PGLP framework, attitude is stressed as an imperative cornerstone toward PGx literacy. Studies have shown that attitude of students, pharmacists or other healthcare providers has leverage on implementing PGx and genetic testing [41, 63-66].

Attitude and knowledge are additional pillars supplemented to improve literacy in PGx/genomics. We imputed a dynamic nature to skills as well as knowledge and attitude. Hence, these elements are interconnected and influence each other and influenced by the sociocultural inputs as well.

\section{Sociocultural influencers of literacy}

The sociocultural determinants of our PGLP framework are more ample than the HLS framework as it incorporates ten inputs: culture, community, patient, media, religion, stakeholders, educational system, laws and ethics, health systems and healthcare providers. We conceptualize that these elements are cross-roads for PGx literacy. The World Health Organization (WHO) apprehended the same sociocultural factors that we appointed in our PGLP framework. Pang [67] named the fragile health care delivery systems as an obstacle to be addressed. Furthermore, WHO advises stakeholders to implement the following strategies to pursue PGx: effective communications, community trust, adopting a multidisciplinary approach to research, mounting ethical and regulatory frameworks, and involving all relevant stakeholders in decision- and policy-making.

Pharmacists are not isolated from the community, health system or other healthcare providers. Consequently, pharmacists in our cohort advocate a multidisciplinary approach to implement PGx. Studies favored this methodology. Caraballo et al. [68] employed a multidisciplinary task force of professionals to strike a balance in the implementation of PGx at the point of care. Another study by Dunnenberger et al. [69] concluded that a multidisciplinary PGx clinic can expedite the incorporation of PGx into clinical care.

In the literature, there is an aggregation of evidence of the PGx's knowledge gap among healthcare providers in general [70-74] and pharmacists $[27,75,76]$ in specific. Preponderance of literacy frameworks is dedicated to patients [30]; however, having a literacy framework for PGx dedicated for healthcare providers will systematically bridge the knowledge gap. The complexity and the multifactorial challenges of the health system coupled with the multidimensional aspects of health literacy necessitate a comprehensive framework to address literacy in PGxs [30, 77].

Assuring a competent healthcare workforce is one of the 10 Essential Public Health Services [78]. It encourages empowering all healthcare providers from all levels with ongoing knowledge. Literacy in PGx is challenged by the unprecedented advances in technology and research in the field coupled by the need of lifelong learning $[26,30$, 47].

\section{How to use the PGLP framework?}

This framework will guide stakeholders in their mission of equipping pharmacists, genetic counselors, doctors and nurses with skills required for the adoption 
and implementation of PGx. PGLP directs the attempts of stakeholders to educate pharmacists on PGx by taking into account their individual factors and tailoring modules to meet their roles, occupation and capabilities whether they are clinical, inpatient, outpatient or community pharmacists or pharmacists in a Pharmacy Therapeutic Committee (PTC) or Institutional Review Board (IRB).

Stakeholders occupied by implementing PGx in their countries should not isolate their approach from the sociocultural factors incubating and nourishing their infrastructure and resources. They have to tailor their map to their current educational system, health system and culture. They have to utilize media and call for laws and policy. Moreover, they need to factor in religion and literacy of the community. The demand for PGx/genomics literacy will kick-start PGx implementation resulting in educational efforts and utilization of the PGLP framework.

Catalyzing the three dynamic pillars of skills, knowledge and attitude of pharmacists or other healthcare providers will be a compelling formula for developing cost-effective personalized and profound modules and approaches. Knowing the pharmacists' skills will guide the stakeholders in purchasing platforms, databases and other resources and will tailor orientation. Mapping the knowledge and attitude of the pharmacists will help shape the resources, workshops, seminars and competencies.

This PGLP framework is comprehensive and we theorize that it will tailor the implementation strategies in a standardized and systematic manner.

\section{Conclusion}

In conclusion, we believe that our framework can be a guide for the implementation of genomic medicine and PGx among pharmacists as it addresses a plethora of individual and sociocultural factors in addition to the skills, demands, knowledge and attitudes of pharmacists. This framework guarantees a holistic bottom-up approach toward PGx implementation. Personalized medicine entails personalized efforts and frameworks. Similar frameworks can be created for other healthcare providers, patients and stakeholders.

The strength of our work is conceptualizing a novel, comprehensive and personalized PGx literacy theoretical framework tailored to pharmacists. Moreover, the PGLP framework is based on the validated theoretical HLS framework that was synthesized upon a number of literacy frameworks thus increasing the PGLP framework's credibility [31]. Furthermore, knowledge and attitude were added as new pillars inherited with PGx literacy. Another strength is building the PGLP framework with mixed methods which added thoroughness and depth.
Moreover, this framework can be used to guide stakeholders in any country that are planning a strategy to implement PGx, as it is comprehensive and systematic. Additionally, this framework can be a platform to PGx literacy to other healthcare providers or even other health-related literacy. It is highly recommended to introduce new courses and training workshops for pharmacists to improve the chances of PGx application as knowledge is an essential and dynamic pillar for the implementation of genomic medicine and PGx. The glitch in navigations skills can be amended by the governing bodies by providing official clinical practice pathways and references for healthcare providers. The PGLP framework is a theoretical framework that needs to be validated. Future research on its implementation can validate this framework. We call researchers to test and validate this PGLP framework to pharmacists and extrapolate it to other healthcare providers.

\section{Acknowledgements \\ The authors would like to thank and acknowledge the participants for offering their time and opinions.}

\section{Authors' contributions}

FAM, ATR, IE, LAA, BRA and GPP conceived and planned the study. ATR and IE developed the interview guide, modulated the focus group sessions, wrote the transcripts verbatim, analyzed the data and drafted the manuscript. ME wrote the transcript verbatim and drafted the manuscript. FAM, LAA, BRA and GPP reviewed the interview guide and the interpretation. All authors read and approved the final manuscript.

\section{Funding}

This study is supported by a grant from Zayed Center for Health Sciences, UAE University Fund code 31R175. The sponsor has no roles in the preparation and analysis of data, or the manuscript. No incentives were given to the pharmacists to participate.

Availability of data and materials

All data generated or analyzed during this study are included in this published article.

\section{Declarations}

Ethics approval and consent to participate

This study was approved by Social Science Research Ethics Committee of United Arab Emirates University ERS_2017_5671.

Consent for publication

Not applicable.

Competing interests

The authors declare that they have no competing interests.

\section{Author details}

${ }^{1}$ Institute of Public Health, College of Medicine and Health Sciences, United Arab Emirates University, P.O. Box 17666, Al Ain, Abu Dhabi, UAE. ${ }^{2}$ Department of Genetics and Genomics, College of Medicine and Health Science, United Arab Emirates University, P.O. Box 17666, Al Ain, Abu Dhabi, UAE. ${ }^{3}$ Zayed Center for Health Sciences, United Arab Emirates University, P.O. Box 17666, Al Ain, Abu Dhabi, UAE. ${ }^{4}$ Department of Pharmacy, School of Health Sciences, University of Patras, 26504 Patras, Greece. 
Received: 11 July 2021 Accepted: 5 October 2021

Published online: 16 October 2021

\section{References}

1. Zhang G, Nebert DW. Personalized medicine: genetic risk prediction of drug response. Pharmacol Ther. 2017;175:75-90. https://doi.org/10. 1016/j.pharmthera.2017.02.036

2. Jarrar Y, Mosleh R, Hawash M, Jarrar Q. Knowledge and attitudes of pharmacy students towards pharmacogenomics among universities in Jordan and west bank of Palestine. Pharmgenomics Pers Med. 2019;12:247-55.

3. Gurwitz D, Weizman A, Rehavi M. Education: teaching pharmacogenomics to prepare future physicians and researchers for personalized medicine. Trends Pharmacol Sci. 2003:24:122-5.

4. Pisanu C, Tsermpini EE, Mavroidi E, Katsila T, Patrinos GP, Squassina A. Assessment of the pharmacogenomics educational environment in southeast Europe. Public Health Genomics. 2014;17:272-9.

5. Gurwitz D. Pharmacogenetics education: 10 years of experience at Tel Aviv University. Pharmacogenomics. 2010;11:647-9.

6. Micaglio E, Locati ET, Monasky MM, Romani F, Heilbron F, Pappone C. Role of pharmacogenetics in adverse drug reactions: an update towards personalized medicine. Front Pharmacol. 2021. https://doi.org/10.3389/ fphar.2021.651720.

7. Hetherington S, Hughes AR, Mosteller M, Shortino D, Baker KL, Spreen W, et al. Genetic variations in HLA-B region and hypersensitivity reactions to abacavir. Lancet. 2002;359:1121-2.

8. Mallal S, Nolan D, Witt C, Masel G, Martin A, Moore C, et al. Association between presence of HLA-B*5701, HLA-DR7, and HLA-DQ3 and hypersensitivity to HIV-1 reverse-transcriptase inhibitor abacavir. Lancet. 2002:359:727-32. https://doi.org/10.1016/S0140-6736(02)07873-X.

9. Hughes AR, Mosteller M, Bansal AT, Davies K, Haneline SA, Lai EH, et al. Association of genetic variations in HLA-B region with hypersensitivity to abacavir in some, but not all, populations. Pharmacogenomics. 2004:5:203-11. https://doi.org/10.1517/phgs.5.2.203.27481.

10. Dean L. Abacavir therapy and HLA-B* 57: 01 genotype drug. Abacavir. 2012;91:1-7.

11. Phillips KA, Veenstra DL, Oren E, Lee JK, Sadee W. Potential role of pharmacogenomics in reducing adverse drug reactions. JAMA. 2001;286:2270. https://doi.org/10.1001/jama.286.18.2270.

12. ASHP statement on the pharmacist's role in clinical pharmacogenomics Am J Heal Pharm. 2015:72:579-81. https://doi.org/10.2146/sp150003.

13. Owusu-Obeng A, Weitzel KW, Hatton RC, Staley BJ, Ashton J, CooperDehoff RM, et al. Emerging roles for pharmacists in clinical implementation of pharmacogenomics. Pharmacotherapy. 2014;34:1102-12. https:// doi.org/10.1002/phar.1481.

14. Wang Y-T, Merl MY, Yang J, Zhu Z-X, Li G-H. Opportunities for pharmacists to integrate pharmacogenomics into clinical practice. Pharmacogenomics J. 2019;20:169-78. https://doi.org/10.1038/s41397-019-0119-8.

15. Bain $\mathrm{KT}$, Knowlton $\mathrm{CH}$, Matos A. Cost avoidance related to a pharmacistled pharmacogenomics service for the program of all-inclusive care for the elderly. Pharmacogenomics. 2020;21:651-61. https://doi.org/10.2217/ pgs-2019-0197.

16. Elewa $H$, Awaisu A. Pharmacogenomics in pharmacy practice: current perspectives. Integr Pharm Res Pract. 2019;8:97-104. https://doi.org/10. 2147/IPRP.S180154

17. Patel JN, Boselli D, Hamadeh IS, Symanowski J, Edwards R, Susi B, et al. Pain management using clinical pharmacy assessments with and without pharmacogenomics in an oncology palliative medicine clinic. JCO Oncol Practice. 2020;16:e166-74. https://doi.org/10.1200/jop.19.00206.

18. Maggo SDS, Sycamore KLV, Miller AL, Kennedy MA. The Three Ps: psychiatry, pharmacy, and pharmacogenomics, a brief report from New Zealand. Front psychiatry. 2019;10:690. https://doi.org/10.3389/fpsyt.2019.00690.

19. Weinstein S, Carroll JC, Jukic S, Mcgivney MS, Klatt P. Perspectives of a pharmacist-run pharmacogenomic service for depression in interdisciplinary family medicine practices. J Am Coll Clin Pharmacy. 2019;3:417-24. https://doi.org/10.1002/jac5.1175.

20. Deininger KM, Page RL, Lee YM, Kauffman YS, Johnson SG, Oreschak K, et al. Non-interventional cardiologists' perspectives on the role of pharmacogenomic testing in cardiovascular medicine. Per Med. 2019;16:12332. https://doi.org/10.2217/pme-2018-0099.
21. Schuh MJ, Crosby S. Description of an established, fee-for-service, officebased. Pharmacist Manag Pharmacogenomics Practice Sr Care Pharm. 2019:34:660-8. https://doi.org/10.4140/TCP.n.2019.660.

22. Berenbrok LA, Hart KM, McGrath SH, Coley KC, Somma McGivney MA, Empey PE. Community pharmacists' educational needs for implementing clinical pharmacogenomic services. J Am Pharm Assoc. 2019;59:539-44. https://doi.org/10.1016/j.japh.2019.03.005.

23. van der Wouden $\mathrm{CH}$, Paasman E, Teichert M, Crone MR, Guchelaar H-J, Swen JJ. Assessing the Implementation of pharmacogenomic panel-testing in primary care in the Netherlands utilizing a theoretical framework. J Clin Med. 2020;9:814. https://doi.org/10.3390/jcm9030814.

24. Gammal RS, Dunnenberger HM, Caudle KE, Swen JJ. Pharmacogenomics education and clinical practice guidelines. Pharmacogenomics. 2019. https://doi.org/10.1016/b978-0-12-812626-4.00015-2.

25. Crown N, Sproule BA, Luke MJ, Piquette-Miller M, McCarthy LM. A continuing professional development program for pharmacists implementing pharmacogenomics into practice. Pharm (Basel, Switzerland). 2020;8:55. https://doi.org/10.3390/pharmacy8020055.

26. Romagnoli KM, Boyce RD, Empey PE, Adams S, Hochheiser H. Bringing clinical pharmacogenomics information to pharmacists: a qualitative study of information needs and resource requirements. Int J Med Inform. 2016;86:54-61. https://doi.org/10.1016/j.jimedinf.2015.11.015.

27. Rahma AT, Elbarazi I, Ali BR, Patrinos GP, Ahmed LA, Al Maskari F, et al. Genomics and pharmacogenomics knowledge, attitude and practice of pharmacists working in United Arab Emirates: findings from focus group discussions - a qualitative study. J Pers Med. 2020;10:134. https://doi.org/ 10.3390/jpm10030134.

28. Wurcel V, Cicchetti A, Garrison L, Kip MMA, Koffijberg H, Kolbe A, et al. The value of diagnostic information in personalised healthcare: a comprehensive concept to facilitate bringing this technology into healthcare systems. Public Health Genomics. 2019;22:8-15. https://doi.org/10.1159/ 000501832.

29. Baker DW. The meaning and the measure of health literacy. J Gen Intern Med. 2006;21:878-83. https://doi.org/10.1111/j.1525-1497.2006.00540.x.

30. Syurina EV, Brankovic I, Probst-Hensch N, Brand A. Genome-based health literacy: a new challenge for public health genomics. Public Health Genomics. 2011;14:201-10. https://doi.org/10.1159/000324238.

31. Squiers $L$, Peinado S, Berkman N, Boudewyns V, McCormack $L$. The health literacy skills framework. J Health Commun. 2012;17:30-54. https://doi. org/10.1080/10810730.2012.713442.

32. Shuster M, Glazewski K, Villa C. Design, development, and evaluation of a teacher workshop enhanced with DNA instructional cases to impact content knowledge and confidence. Interdiscip J Probl Learn. 2020;14:1-22.

33. McClaren BJ, Crellin E, Janinski M, Nisselle AE, Ng L, Metcalfe SA, et al. Preparing medical specialists for genomic medicine: continuing education should include opportunities for experiential learning. Front Genetics. 2020;11:151. https://doi.org/10.3389/fgene.2020.00151.

34. Martins A, Fonseca MJ, Lemos M, Lencastre L, Tavares F. Bioinformaticsbased activities in high school: fostering students' literacy, interest, and attitudes on gene regulation, genomics, and evolution. Front Microbiol. 2020;11:2410. https://doi.org/10.3389/fmicb.2020.578099.

35. Tsai Y-S, Perrotta C, Gašević D. Empowering learners with personalised learning approaches? Agency, equity and transparency in the context of learning analytics. Assess Eval High Educ. 2019;45:554-67. https://doi.org/ 10.1080/02602938.2019.1676396.

36. Berlin DS, Person MG, Mittal A, Oppezzo MA, Chin DB, Starr B, et al. DNATwist: a web-based tool for teaching middle and high school students about pharmacogenomics. Clin Pharmacol Ther. 2010;87:393-5.

37. Gálvez-Peralta M, Szklarz GD, Geldenhuys WJ, Lockman PR. An effective approach to teaching pharmacogenomics in the first year of pharmacy curriculum. Am J Pharm Educ. 2018;82:6345

38. Patrinos GP, Katsila T. Pharmacogenomics education and research at the Department of Pharmacy, University of Patras. Greece Pharmacogen. 2016:17:1865-72. https://doi.org/10.2217/pgs-2016-0142.

39. Lee KC, Ma JD, Hudmon KS, Kuo GM. A train-the-trainer approach to a shared pharmacogenomics curriculum for US colleges and schools of pharmacy. Am J Pharm Educ. 2012;76:193. https://doi.org/10.5688/ajpe7 610193.

40. Garten Y, Altman RB. Teaching computers to read the pharmacogenomics literature ... so you don't have to. Pharmacogenomics. 2010;11:515-8. https://doi.org/10.2217/pgs.10.48. 
41. Assem M, Broeckel U, MacKinnon GE. Personal DNA testing increases pharmacy students' confidence and competence in pharmacogenomics. Am J Pharm Educ. 2020. https://doi.org/10.5688/ajpe8249.

42. Ward KM, Taubman DS, Pasternak AL, Burghardt KJ, Ellingrod VL, Parikh SV. Teaching psychiatric pharmacogenomics effectively: evaluation of a novel interprofessional online course. J Am Coll Clin Pharm. 2020;4:176-83.

43. Nicholson WT, Formea CM, Matey ET, Wright JA, Giri J, Moyer AM. Considerations when applying pharmacogenomics to your practice. Mayo Clin Proc. 2021;96:218-30. https://doi.org/10.1016/j.mayocp.2020.03.011.

44. Bain KT, Schwartz EJ, Knowlton OV, Knowlton CH, Turgeon J. Implementation of a pharmacist-led pharmacogenomics service for the Program of All-Inclusive Care for the Elderly (PHARM-GENOME-PACE). J Am Pharm Assoc. 2018;58:281-289.e1. https://doi.org/10.1016/j.japh.2018.02.011.

45. Hicks JK, Stowe D, Willner MA, Wai M, Daly T, Gordon SM, et al. Implementation of clinical pharmacogenomics within a large health system: from electronic health record decision support to consultation services. Pharmacother J Hum Pharmacol Drug Ther. 2016;36:940-8. https://doi. org/10.1002/phar.1786.

46. Schuh MJ, Crosby S. Methotrexate central nervous system toxicity identified in a pharmacogenomics pharmacist consult patient. Sr Care Pharm. 2019;34:595-9. https://doi.org/10.4140/tcp.n.2019.595.

47. Owen JA. Integrating pharmacogenomics into pharmacy practice via medication therapy management. J Am Pharm Assoc. 2011;51:e64-74. https://doi.org/10.1331/japha.2011.11543.

48. Schwartz EJ, Issa AM. The role of hospital pharmacists in the adoption and use of pharmacogenomics and precision medicine. Per Med. 2017;14:27-35. https://doi.org/10.2217/pme-2016-0063.

49. Rahma AT, Elbarazi I, Ali BR, Patrinos GP, Ahmed LA, AlMaskari F. Stakeholders 'interest and attitudes toward genomic medicine and pharmacogenomics implementation in the United Arab Emirates : a qualitative study. Public Health Genomics. 2021.

50. Denic S, Aden B, Nagelkerke N, Essa AA. $\beta$-thalassemia in Abu Dhabi: consanguinity and tribal stratification are major factors explaining the high prevalence of the disease. Hemoglobin. 2013;37:351-8. https://doi. org/10.3109/03630269.2013.790827.

51. Al-Jasmi FA, Tawfig N, Berniah A, Ali BR, Taleb M, Hertecant JL, et al. Prevalence and novel mutations of lysosomal storage disorders in United Arab Emirates: LSD in UAE. JIMD Rep. 2013;10:1-9. https://doi.org/10.1007/ 8904_2012_182.

52. Freedman DA, Bess KD, Tucker HA, Boyd DL, Tuchman AM, Wallston KA. Public health literacy defined. Am J Prev Med. 2009;36:446-51. https:// doi.org/10.1016/j.amepre.2009.02.001.

53. Peterson-Clark G, Aslani P, Williams KA. Pharmacists' online information literacy: an assessment of their use of Internet-based medicines information. Heal Inf Libr J. 2010;27:208-16. https://doi.org/10.1111/j.1471-1842. 2010.00891.x

54. Basheti IA, Armour CL, Reddel HK, Bosnic-Anticevich SZ. Long-term maintenance of pharmacists' inhaler technique demonstration skills. Am J Pharm Educ. 2009;73:32. https://doi.org/10.5688/aj730232.

55. Caudle KE, Klein TE, Hoffman JM, Muller DJ, Whirl-Carrillo M, Gong L, et al. Incorporation of pharmacogenomics into routine clinical practice: the clinical pharmacogenetics implementation consortium (CPIC) guideline development process. Curr Drug Metab. 2014;15:209-17. https://doi.org/ 10.2174/1389200215666140130124910.

56. Thorn CF, Klein TE, Altman RB. PharmGKB: the pharmacogenetics and pharmacogenomics knowledge base. Pharmacogenomics. 2005. https:// doi.org/10.1385/1-59259-957-5:179.

57. Nagy M, Lynch M, Kamal S, Mohamed S, Hadad A, Abouelnaga S, et al. Assessment of healthcare professionals' knowledge, attitudes, and perceived challenges of clinical pharmacogenetic testing in Egypt. Per Med. 2020;17:251-60. https://doi.org/10.2217/pme-2019-0163.

58. Papastergiou J, Tolios P, Li W, Li J. The innovative Canadian pharmacogenomic screening initiative in community pharmacy (ICANPIC) study. J Am Pharm Assoc. 2017;57:624-9. https://doi.org/10.1016/j.japh.2017.05. 006.
59. Formea CM, Nicholson WT, McCullough KB, Berg KD, Berg ML, Cunningham $J L$, et al. Development and evaluation of a pharmacogenomics educational program for pharmacists. Am J Pharm Educ. 2013;77:10. https://doi.org/10.5688/ajpe77110.

60. Benzeroual KE, Shah B, Shinde S. Pharmacogenomics: assessing educational exposure, confidence in knowledge and training elements of pharmacists. Per Med. 2012;9:387-93. https://doi.org/10.2217/pme.12. 44.

61. Hesse BW, Nelson DE, Kreps GL, Croyle RT, Arora NK, Rimer BK, et al. Trust and sources of health information. Arch Intern Med. 2005;165:2618. https://doi.org/10.1001/archinte.165.22.2618.

62. Nelson DE, Hesse BW, Croyle RT. Making data talk: the science and practice of translating public health research and surveillance findings to policy makers, the public, and the press. Oxford University Press; 2009. https://doi.org/10.1093/acprof:oso/9780195381535.001.0001.

63. Alejielat R, Ejielat Z, Andrawes S, Mhaidat NM. An evaluation of the knowledge, opinions, expectations and concerns toward pharmacogenomics among Jordanian pharmacists. Per Med. 2016;13:143-54. https://doi.org/10.2217/pme.15.50.

64. Rahma AT, Elsheik M, Elbarazi I, Ali BR, Patrinos GP, Kazim MA, et al. Knowledge and attitudes of medical and health science students in the United Arab Emirates toward genomic medicine and pharmacogenomics: a cross-sectional study. J Pers Med. 2020;10:191. https://doi. org/10.3390/jpm10040191.

65. Olwi D, Merdad L, Ramadan E. Knowledge of genetics and attitudes toward genetic testing among college students in Saudi Arabia. Public Health Genomics. 2016;19:260-8. https://doi.org/10.1159/000446511.

66. Elewa H, Alkhiyami D, Alsahan D, Abdel-Aziz A. A survey on the awareness and attitude of pharmacists and doctors towards the application of pharmacogenomics and its challenges in Qatar. J Eval Clin Pract. 2015;21:703-9. https://doi.org/10.1111/jep.12372.

67. Pang T. Pharmacogenomics and personalized medicine for the developing world-too soon or just-in-time? A personal view from the World Health Organization. Curr Pharmacogenomics Person Med 2009;7:149-57. https://doi.org/10.2174/1875692110907030149.

68. Caraballo PJ, Hodge LS, Bielinski SJ, Stewart AK, Farrugia G, Schultz CG, et al. Multidisciplinary model to implement pharmacogenomics at the point of care. Genet Med. 2017;19:421-9. https://doi.org/10.1038/gim. 2016.120.

69. Dunnenberger HM, Biszewski M, Bell GC, Sereika A, May H, Johnson SG, et al. Implementation of a multidisciplinary pharmacogenomics clinic in a community health system. Am J Health Syst Pharm. 2016;73:195666. https://doi.org/10.2146/ajhp160072.

70. Rahma AT, Elsheik M, Ali BR, Elbarazi I, Patrinos GP, Ahmed LA, et al. Knowledge, attitudes, and perceived barriers toward genetic testing and pharmacogenomics among healthcare workers in the United Arab Emirates: a cross-sectional study. J Pers Med. 2020;10:216. https://doi. org/10.3390/jpm10040216.

71. Abdela OA, Bhagavathula AS, Gebreyohannes EA, Tegegn HG. Ethiopian health care professionals' knowledge, attitude, and interests toward pharmacogenomics. Pharmgenomics Pers Med. 2017;10:279_ 85. https://doi.org/10.2147/PGPM.S145336.

72. Giri J, Curry TB, Formea CM, Nicholson WT, Rohrer Vitek CR. Education and knowledge in pharmacogenomics: still a challenge? Clin Pharmacol Ther. 2018;103:752-5. https://doi.org/10.1002/cpt.1019.

73. Tsermpini EEE, Stamopoulou T, Kordou Z, Barba E, Siamoglou S, Stathoulias A, et al. Continuous pharmacogenomics and genomic medicine education for healthcare professionals through electronic educational courses. Per Med. 2019;16:189-93. https://doi.org/10.2217/ pme-2019-0014

74. Kim WYY, Kim HSS, Oh M, Shin JGG. Survey of physicians'views on the clinical implementation of pharmacogenomics-based personalized therapy. Transl Clin Pharmacol. 2020;28:34-42. https://doi.org/10. 12793/tcp.2020.28.e6.

75. Muzoriana N, Gavi S, Nembaware V, Dhoro M, Matimba A. Knowledge, attitude, and perceptions of pharmacists and pharmacy students 
towards pharmacogenomics in Zimbabwe. Pharm (Basel, Switzerland). 2017;5:36. https://doi.org/10.3390/pharmacy5030036.

76. Karuna N, Tragulpiankit P, Mahasirimongkol S, Chumnumwat S. Knowledge, attitude, and practice towards pharmacogenomics among hospital pharmacists in Thailand. Pharmacogenet Genomics. 2020;30:73-80. https://doi.org/10.1097/fpc.0000000000000399.

77. Qiang Z. Internationalization of higher education: towards a conceptual framework. Policy Futures Educ. 2003;1:248-70. https://doi.org/10.2304/ pfie.2003.1.2.5
78. CDC. 10 Essential Public Health Services. 2020. https://www.cdc.gov/ publichealthgateway/publichealthservices/originalessentialhealthse rvices.html.

\section{Publisher's Note}

Springer Nature remains neutral with regard to jurisdictional claims in published maps and institutional affiliations.
Ready to submit your research? Choose BMC and benefit from:

- fast, convenient online submission

- thorough peer review by experienced researchers in your field

- rapid publication on acceptance

- support for research data, including large and complex data types

- gold Open Access which fosters wider collaboration and increased citations

- maximum visibility for your research: over $100 \mathrm{M}$ website views per year

At BMC, research is always in progress.

Learn more biomedcentral.com/submissions 